\title{
Load-Frequency Control Assessment using Restoration Index with Artificial Bee Colony Algorithm for Interconnected Power System with Disturbance Accommodation Controller
}

\author{
R. Jayanthi \\ Department of Electrical Engineering \\ Annamalai University \\ Annamalai Nagar- 608002 \\ Tamil Nadu, India
}

\author{
I. A. Chidambaram \\ Department of Electrical Engineering \\ Annamalai University \\ Annamalai Nagar- 608002 \\ Tamil Nadu, India
}

\begin{abstract}
Based on the concept of Modern Control theory, an optimal robust power system controller for power restoration problem using Disturbance Accommodation theory has been adopted in this paper. This proposed methodology is applied to a TwoArea Two-Unit thermal Reheat Interconnected Power System (TATURIPS) taking into account of Super Conducting Magnetic Energy Storage (SMES) device and Gas Turbine (GT) unit in either area to meet out the system uncertainties due to various disturbances. For Load-Frequency Control (LFC) a decentralized PI controller for each area and a centralized Disturbance Accommodation Controller (DAC) in TATURIPS co-ordinated with SMES and GT units as back-up energy suppliers have been implemented in this proposed methodology. Feasible Restoration Index (FRI) and Complete Restoration Index (CRI) are computed for various disturbances based on settling time of the output response of the system and the control input deviation. The decentralized controller is tuned using the Artificial Bee Colony (ABC) algorithm. With these two Restoration Indices obtained from the Intelligent Controller (IC) as well as DAC, the conditions required to be satisfied in ensuring the restoration of the power system are listed out and with proper implementation will result in high degree of reliability and stability of power supply reducing the frequency deviations to a greater extent and the settling time is also reduced to a minimum time span.
\end{abstract}

\section{Keywords}

Restoration Index, Disturbance Accommodation Controller, Settling Time, Proportional-Integral Controller, Artificial Bee Colony.

\section{INTRODUCTION}

In the interconnected power systems there are number of control areas or units and each control area has to generate the required amount of power to satisfy the customer load requirements as well as it has to maintain the system frequency, tie-line power deviation, control input requirements within the scheduled levels. A high gain may deteriorate the system performance leading to instability of the system. Therefore, in order to maintain the load generations balance and the quality of power at requisite level an intelligent decentralized PI controller using Artificial Bee Colony (ABC) algorithm accompanied with a centralized DAC controller has been proposed to reduce the oscillations due to frequency deviations and also to minimize the time span of settling time[1]. When an incident occurs on the system frequency within the stipulated limits is a major priority and if these limits are breached, then the magnitude of the excursion needs to be restricted and the frequency has to return within the limits as quick as possible. Therefore, based upon optimal control strategy an approach has been constructed which controls all the power generating stations. In the modern control theory concept the design of an intelligent decentralized controller in the system within the area is required where the local system variables are controlled. Due to the requirement of perfect model, which has to track the state variables and satisfy the system constraints, ABC tuned Proportional-Integral (PI) controller along with Disturbance Accommodation Controller with addition of a small capacity SMES unit and GT units to the system significantly improves the transients of frequency, tieline power deviations and reduces the settling time span against load changes. SMES and GT units with a minimum capacity can be applied not only as a fast energy compensation device for large loads but also to damp out the frequency and tie-line power deviations, which makes it a cost-effective system. Moreover Gas Turbines become increasingly popular in different power systems due to their green house emission as well as higher efficiency especially when connected in a combined cycle setup [2,3]. Various case studies has been analyzed for $1 \%$ and $4 \%$ disturbances and Restoration Indices are obtained from the simulation results and Restoration Indices, the required control efforts can be determined to provide a good control over the uncertain disturbances occurring in the system.

\section{MODELING OF THE TATURIPS}

An interconnected power system is considered wherein twoarea having two-units in each where all generators are considered to act as coherent group. The power system investigated in this study is shown in figure 1 . The detailed block diagram is given in figure 2 and the system data is provided in the appendix. Under normal operating conditions a power system is continually subjected to small random-like disturbances. These typically take the form of small changes in the scheduled generation of the system in addition of a small load to the network. This transient of a power system following a disturbance is generally oscillatory in nature, which results in momentary oscillations in power flow in the transmission system. To deal effectively with these unknown, 
uncontrollable system variables, the controller design must be able to model their anticipated performances using a classical approach.

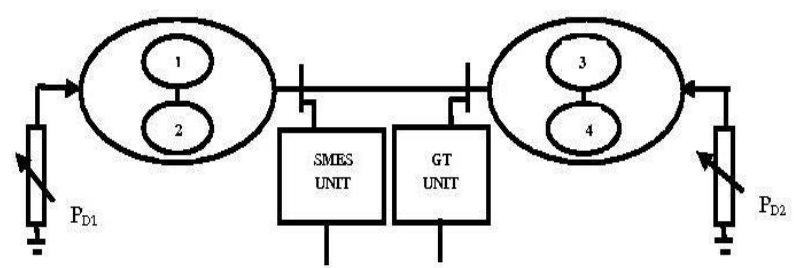

Fig 1: TATURIPS with SMES and GT units

The generation changes must be made to match the load perturbation at the nominal conditions, if the normal state is to be maintained. The mismatch in the real power balance affects primarily the system frequency but leaves the bus voltage magnitude essentially unaffected. In a power system, it is desirable to achieve better frequency constancy than obtained by the speed governing system alone. This requires that each area should take care of its own load changes, such that schedule tie power can be maintained. A two-area interconnected system dynamic model in state variable form can be conveniently obtained from the transfer function model. The state variable equation of the minimum realization model of the ' $\mathrm{N}$ ' area interconnected power system is expressed as [4]

$$
\begin{gathered}
\dot{X}=A x+B u+\tau d \\
Y=C x
\end{gathered}
$$

Where, the system state vector $\mathrm{X}$ consists of the following variables as

$[x]$

$$
\begin{gathered}
=\left[\int A C E_{1} d t, \int A C E_{2} d t, \Delta F_{1}, \Delta P_{g 1}, \Delta P_{r 1}, \Delta X_{e 1}, \Delta P_{t i e l}, \Delta F_{2}, \Delta P_{g 2}, \Delta P_{r 2,}, \Delta X_{e 2}\right]^{T} \\
\text { System control input vector is }[u]=\left[\begin{array}{l}
\Delta P_{c 1} \\
\Delta P_{c 2}
\end{array}\right] \\
\text { System disturbance input vector is }[d]=\left[\begin{array}{l}
\Delta P_{d 1} \\
\Delta P_{d 2}
\end{array}\right]
\end{gathered}
$$

A is system matrix, $\mathrm{B}$ is the input distribution matrix and $\Gamma$ disturbance distribution matrix, $x$ is the state vector, $u$ is the control vector and $d$ is the disturbance vector of load changes of appropriate dimensions. The typical values of system parameters for nominal operation condition are given in appendix. This study focuses on optimal tuning of controllers for LFC and tie-power control using settling time based optimization to ensure a better power system restoration assessment. On the other hand in this study the goals are to control the frequency and inter area tie-power with good oscillation damping using the modern control theory concept and also to obtain a good performance under all operating conditions with various loading conditions and finally to design a low-order controller for easy implementation. To achieve the above said conditions a Feasible Restoration Index (FRI) and Complete Restoration Index (CRI) based on the settling time has been formulated in this proposed methodology in TATURIPS with the SMES unit and GT unit in Area-1and
Area-2 respectively. Their Proportional (P) and Integral (I) gains has been optimized in addition with that of a Disturbance Accommodation Controller to achieve the improved restoration. Transfer function model of the two-area two-unit thermal reheat interconnected system used for implementation is as shown in figure 2 .

\subsection{Problem Formulation of TATURIPS With DAC}

The linear frequency control problem for a TATURIPS may be stated as follows, in which the $\mathrm{N}$-area problem can be defined by [5]

$$
\begin{gathered}
\dot{x}(t)=A(t) X(t)+B(t) U(t)+F(t) W(t) \\
Y(t)=C(t) X(t)
\end{gathered}
$$

Where $X, U$ and $W$ are state, control and disturbance vectors and $Y$ is the system output. The TATURIPS is ideally defined by a set of state variables including the control input (speed changer position) and disturbance input (area load variation) in each area. As in this study the disturbances are treated as initial conditions on the system state variables, mathematically it can be modeled as a weighted linear combination of a set of known functions [6]

$$
W(t)=C_{1} f_{1}(t)+C_{2} f_{2}(t)+, \ldots .,+C_{m} f_{m}(t)
$$

Where the function $f_{i}(t)$ represent the various waveform patterns that can be obtained from the daily load pattern and $C_{i}$ is piecewise random constant parameter. Therefore, the overall power system disturbances for TATURIPS using DAC can be [5] modeled as

$$
w=W(z, t)
$$

$\dot{z}=Z(z, t)+\sigma(t) ; \quad z=\left(z_{1}, z_{2}, \ldots, z_{\rho}\right)$

Which is the proposed mathematical model for disturbances having waveform structure recognized as the state-variable equation (1), where $\rho$-dimensional vector $\mathrm{z}(\mathrm{t})$ in (7) define the state of the disturbance which is considered to be a fictitious quantity. In particular, it is the value of the instantaneous state $\mathrm{z}(\mathrm{t})$ of an uncertain disturbance $\mathrm{w}(\mathrm{t})$, that contains all necessary information to make on-line decision of the control $u$ at time $t$, even if the future disturbances are unknown quantities. Figure 3 shows the $i^{\text {th }}$ control area diagram. Where the state variables containing the essential information about the $i$ th area can be defined as in (3).

Apart from the usual representation of the uncertain disturbances $w_{i}$ use is made of the waveform model (7). As referred from [5] a set of three basis functions $f_{1}=1, f_{2}=$ $t, f_{3}=e^{-a t}$ is chosen to represent the actual load pattern which gives approximately a range of waveform pattern. Therefore $W(t)$ is modeled as 


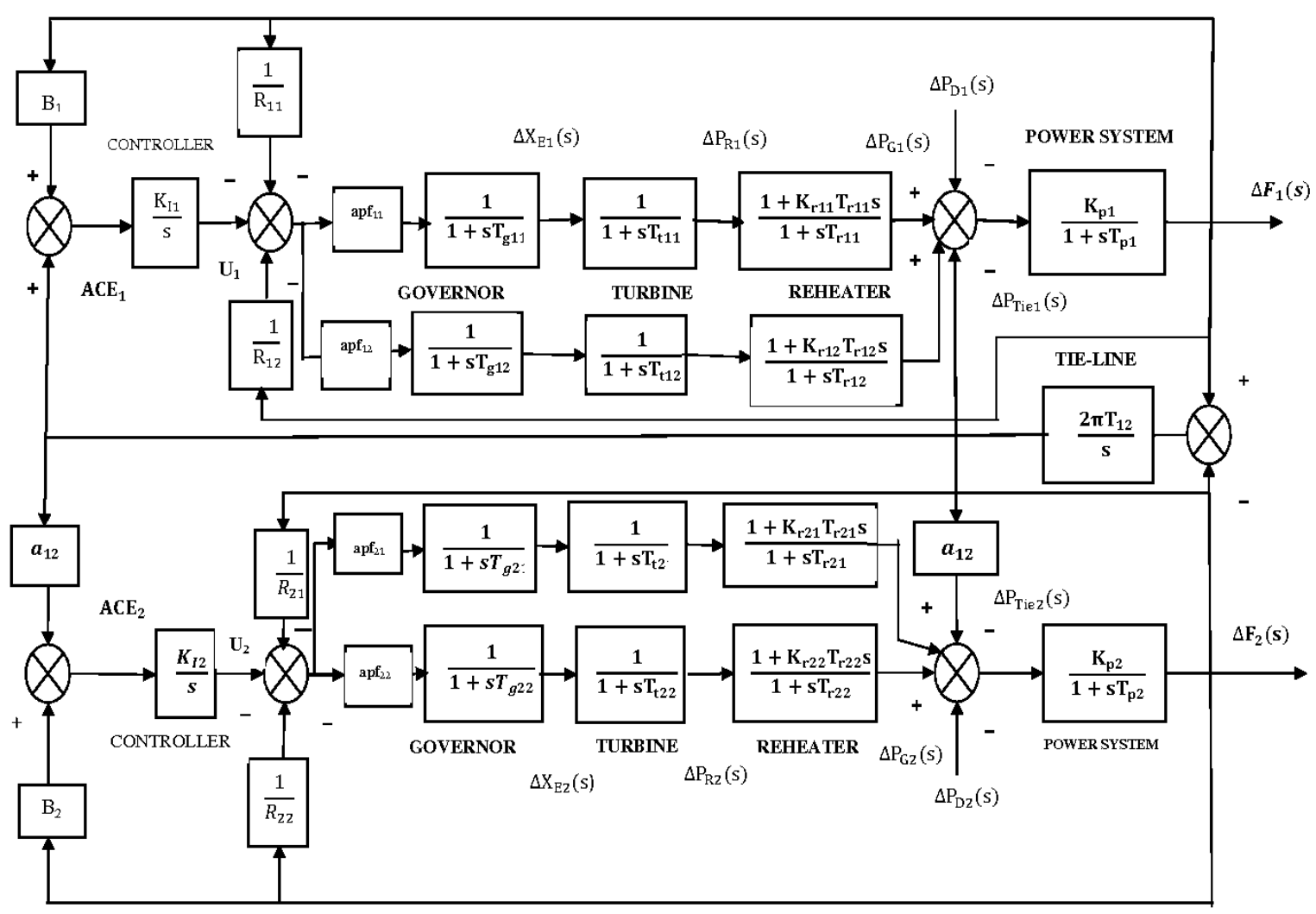

Fig 2: The TATURIPS

$W(t)=C_{1}+C_{2} t+C_{3} t e^{-a t}$

The primary objective of the control $U$ is to maintain the regulation of area frequency while simultaneously counteracting the system disturbances. In DAC, in particular the maximum absorbing mode of the critical state variable which is the frequency control as per the analysis using DAC can be used to design the controller that automatically uses the action of system disturbances to achieve an effective restoration of the electric power system.

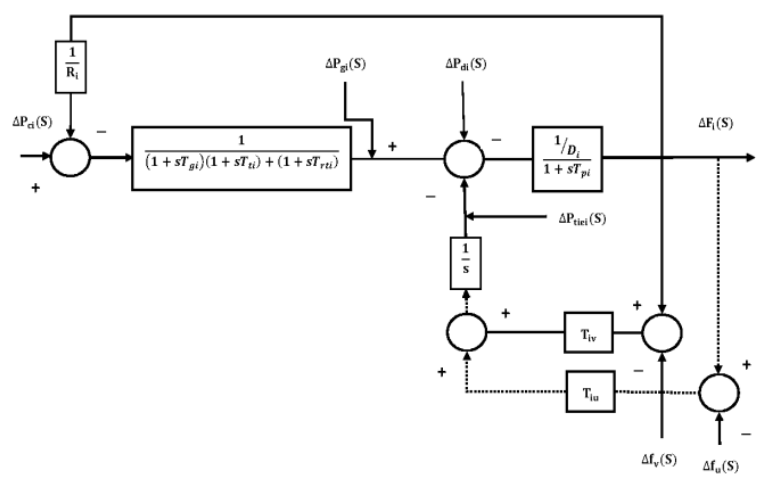

Fig 3: Block diagram of $i^{\text {th }}$ control area

\subsection{Application of DAC in TATURIPS}

Single area representation of the Two-Area Two-Unit Reheat thermal Interconnected Power System is denoted by the system state and control variables as $X_{1}=\Delta f, X_{2}=\Delta P, X_{3}=\Delta X_{g}$ $U=\Delta P_{c}$.The system matrices $\mathrm{A}, \mathrm{B}, \mathrm{C}$ and $\mathrm{F}$ in this case can be obtained from the same as

$$
\begin{gathered}
A=\left[\begin{array}{ccc}
f^{*} / 2 H & f^{*} / 2 H & 0 \\
0 & -1 / T_{t} & 1 / T_{t} \\
-1 / T_{g} R & 0 & -1 / T_{g}
\end{array}\right] ; B=\left[\begin{array}{c}
0 \\
0 \\
1 / T_{g}
\end{array}\right] ; \\
C=\left[\begin{array}{lll}
1, & 0, & 0
\end{array}\right] ; F=\left[\begin{array}{c}
f^{*} / 2 H \\
0 \\
0
\end{array}\right]
\end{gathered}
$$

To achieve the objective of control $U$, that is to maintain the frequency to the nominal value and tie-line power deviation close to zero by counteracting with the disturbances in the system one can choose to minimize the performance index of the form

$$
\begin{aligned}
\operatorname{Min} J\left(U ; X_{0}, t_{0}, T\right)= & \frac{1}{2} X^{T}(T) S X(T) \\
& +\frac{1}{2} \int_{t_{0}}^{T}\left[X^{T}(t) Q X(t)+U^{T}(t) R U(t) d t\right]
\end{aligned}
$$

Where ' $S$ ' and ' $Q$ ' are symmetric non-negative matrices of appropriate dimensions and ' $R$ ' is positive definite. Now, the theory of DAC can be optimally used to accommodate the disturbances in the load frequency control problem. 


\subsection{Disturbance Absorption for a Critical State Variable}

In this paper for the Two-Area Two-Unit Reheat Interconnected Power System, the system frequency deviation is considered to be the prime factor of load changes and analysis has been carried out to minimize the disturbance effect to a maximum by absorbing the system frequency deviation to a maximum extent by considering the total effect of disturbances $W(t)$ on just the system frequency deviation $X_{I}$ which is nothing but the critical variable control problem. To absorb the disturbance effects on the area frequency DAC 'critical variable' control action is considered. The differential equation governing $X_{1}=\Delta \mathrm{f}$ alone can be obtained from state expressions, by repeated differentiation $U_{c}(t)$ is obtained, which is designed to counteract the disturbance effects on $X_{1}$ and simultaneously regulate $X_{1} \rightarrow 0$.The total control $U(\mathrm{t})$ can be expressed [3] by

$$
\begin{gathered}
U(t)=K_{z} Z(t)+K_{x} X(t) \\
U(t)=K_{z} \hat{Z}(\mathrm{t})+K_{x} \hat{X}(\mathrm{t})
\end{gathered}
$$

Where $\hat{Z}(\mathrm{t})$ and $\hat{X}(\mathrm{t})$ are accurate estimates of $\mathrm{Z}(\mathrm{t})$ and $\mathrm{X}(\mathrm{t})$ which will be obtained from $\mathrm{Y}(\mathrm{t})$ on online, real-time state reconstructer.

\subsection{SMES UNIT}

The Superconducting Magnetic Energy Storage (SMES) system is a fast acting device which can damp out these oscillations and help in reducing the frequency and tieline Power deviations for better performance of system disturbances. It is designed to store electric energy in the low loss superconducting coil. Power can be absorbed or released from the coil according to the system requirement. A super conducting magnetic energy storage(SMES) is capable of controlling active and reactive power simultaneously and has been expected as one if the most effective stabilizers of power oscillations[7,8]. The schematic diagram in Fig.4 shows the configuration of a thyristor controlled SMES unit. The SMES unit contains DC superconducting Coil and converter which is connected by $\mathrm{Y}-\mathrm{D} / \mathrm{Y}-\mathrm{Y}$ transformer. The inductor is initially charged to its rated current $\mathrm{I}_{\mathrm{d} 0}$ by applying a small positive voltage. Once the current reaches the rated value, it is maintained constant by reducing the voltage across the inductor to zero since the coil is superconducting [9]. Neglecting the transformer and the converter losses, the DC voltage is given by

$E_{d}=2 V_{d o} \cos \alpha-2 I_{d} R_{c}$

Where $E_{d}$ is DC voltage applied to the inductor $(\mathrm{kV})$, firing angle $(\alpha), I_{d}$ is current flowing through the inductor $(k A) . R_{c}$ is equivalent commutating resistance $(\mathrm{V})$ and $\mathrm{V}_{\mathrm{d} 0}$ is maximum circuit bridge voltage $(\mathrm{kV})$. Charge and discharge of SMES unit are controlled through change of the commutation angle $\alpha$.

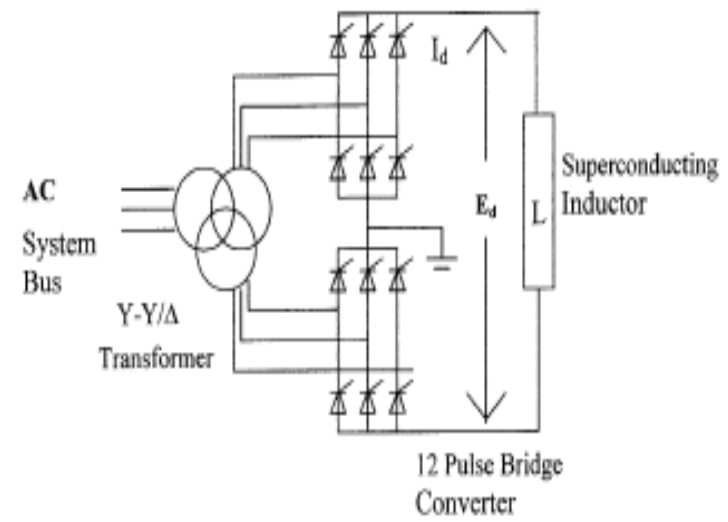

Fig 4: Schematic diagram of SMES unit

In LFC operation, the dc voltage $\mathrm{E}_{\mathrm{d}}$ across the superconducting inductor is continuously controlled depending on the sensed area control error (ACE) signal. Moreover, the inductor current deviation is used as a negative feedback signal in the SMES control loop. So, the current variable of SMES unit is intended to be settling to its steady state value. If the load is used as a negative feedback signal in the SMES control demand changes suddenly, the feedback provides the prompt restoration of current. The inductor current must be restored to its nominal value quickly after a system disturbance, so that it can respond to the next load disturbance immediately. As a result, the energy stored at any instant is given by

$$
W_{s m}=W_{s m 0}+\int_{t_{0}}^{t} P_{s m}(\tau) d \tau
$$

Where,

$W_{s m 0}=\frac{1}{2} L I_{d o}^{2}$, initial energy in the inductor.

Equations of inductor voltage deviation and current deviation for each area in Laplace domain are as follows

$$
\begin{aligned}
& \Delta E_{d i}(s)= \\
& \left(\frac{K_{\text {SMES }}}{1+s T_{d c i}}\right) U_{\text {smesi }}(s)-\frac{K_{i d}}{1+s T_{d c i}} \Delta I_{d i}(s) \\
& \Delta I_{d i}(s)=\left(\frac{1}{s L i}\right) \times \Delta E_{d i}(s)
\end{aligned}
$$

Where,

$$
\begin{array}{ll}
\Delta E_{d i}(s)= & \text { converter voltage deviation applied to inductor in } \\
& \text { SMES unit } \\
\mathrm{K}_{\mathrm{SMES}}= & \text { Gain of the control loop SMES } \\
\mathrm{T}_{\mathrm{dci}}= & \text { converter time constant in SMES unit } \\
\mathrm{K}_{\mathrm{id}}= & \text { gain for feedback } \Delta \mathrm{Id} \text { in SMES unit. } \\
\Delta I_{d i}(s)= & \text { inductor current deviation in SMES unit }
\end{array}
$$

The deviation in the inductor real power of SMES unit is expressed in time domain as follows

$\Delta P_{S M E S i}=\Delta E_{d i} I_{d i}+\Delta E_{d i} i_{d i}$

Figure 5 shows the block diagram of the SMES unit. To achieve quick restoration of the current, the inductor current deviation can be sensed and used as a negative feedback signal in the SMES control loop. 


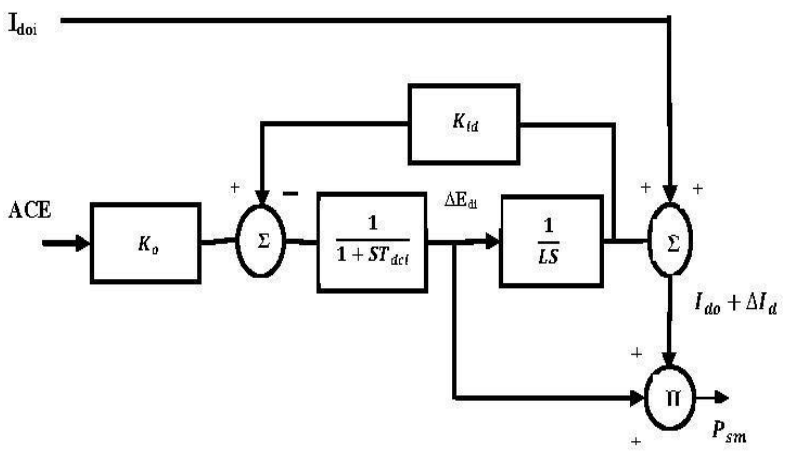

Fig 5: Block diagram of SMES unit

In a two-area interconnected thermal power system under study with the sudden small disturbances which continuously disturb the normal operation of power system. As a result the requirement of frequency controls of areas beyond the governor capabilities SMES is located in area1 absorbs and supply required power to compensate the load fluctuations in area1. The inductor is initially charged to its rated current $I_{d o}$ by applying a small positive voltage. Once the current reaches the rated value it is maintained constant by reducing the voltage across the inductor to zero since the coil is superconducting [10]. Tie-line power flow monitoring is also required in order to avoid the blackout of the power system. The Input of the integral controller of each area is

$A C E_{i}=\beta_{i} \Delta f_{i}+\Delta P_{t i e}$

Where,

$\beta_{\mathrm{i}}=$ frequency bias in area $\mathrm{i}$

$\Delta \mathrm{f}_{\mathrm{i}} \quad=$ frequency deviation in area $\mathrm{i}$

$\Delta \mathrm{P}_{\text {tie I }}=$ Net tie power flow deviation in area

SMES unit has the advantages that the time delay during charge and discharge is quite short, Capable of controlling both active and reactive power simultaneously, loss of power is less, highly reliable and efficient also.

\subsection{GAS TURBINE UNIT}

Amid growing concerns about green house emissions, gas turbines have been touted as a viable option, due to their higher efficiency and the lower green house emissions compared to other energy sources and fast starting capability which enables them to be often used as peaking units that respond to peak demands. Many models representing the gas turbines have been developed over the years. A GAST model as shown in figure 6 which is one of the most commonly used dynamic models has been used in this methodology [11, 12].Gas Turbines have the advantages like Quick start-up/shut-down, low weight and size, cost of installation is less, low capital cost, Black-start capability, high efficiency requires less cranking power, pollutant emission control etc., This gives approximately two-thirds of the total power of a typical combined cycle power plant. When the load is suddenly increased the speed drops quickly but the regulator reacts and increases the fuel flow to a maximum of $100 \%$, thereby improving the efficiency of the system.

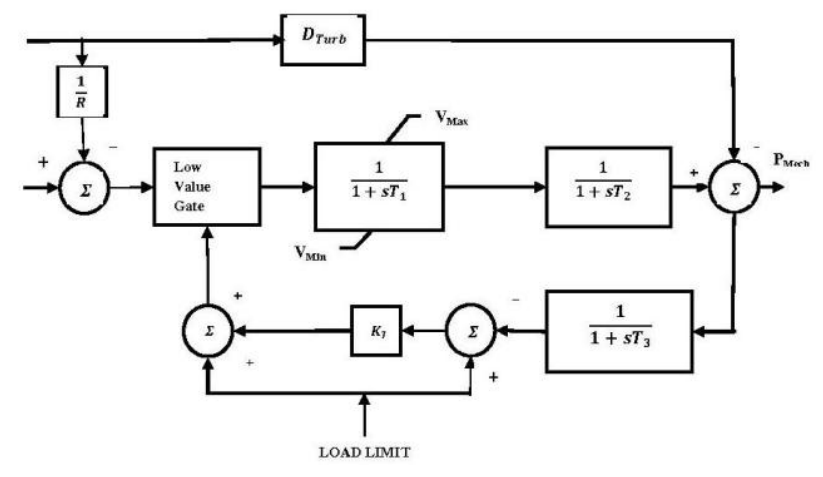

Fig 6: Gas Turbine Model

\section{Controller design using Artificial Bee Colony Optimization technique for the LFC assessment problem}

The Artificial Bee Colony $[\mathrm{ABC}]$ algorithm which was introduced in 2005 by Karaboga, is used as an optimization search, simulates the intelligent foraging behavior of a honey bee swarm. It incorporates a flexible and well-balanced mechanism to adapt to the global and local exploration and exploitation abilities within a short computation time. Due to its simplicity and easy implementation, the $\mathrm{ABC}$ algorithm has captured much attention and has been applied to solve many practical optimization problems [13]. This method is efficient in handling large and complex search spaces and it has also been found to be robust in solving problems featuring nonlinearity, no differentiability and high dimensionality. Compared with the usual algorithms, the major advantage of $\mathrm{ABC}$ algorithm lays in that it conducts both global search and local search in each iteration and as a result the probability of finding the optimal parameters is significantly increased, which efficiently avoid local optimum to a large extent.

In the $\mathrm{ABC}$ algorithm, the colony of artificial bees contains three groups of bees: Employed bees, Onlookers and Scouts. A bee waiting on the dance area for making decision to choose a food source is called an Onlooker and a bee going to the food source visited by it previously is named an employed bee. A bee carrying out random search is called a Scout. Communication among bees about the quality of food sources is being achieved in the dancing area by performing waggle dance. In the $\mathrm{ABC}$ algorithm, first half of the colony consists of employed artificial bees and the second half constitutes the Onlookers. In other words, the number of employed bees is equal to the number of food sources around the hive. The employed bee whose food source is exhausted by the employed and onlooker bees becomes a scout. The main steps of the algorithm are given below [14]:

1. The search process starts with the random initialization of the bee population.

2. According to the numerical objective functions being examined, the non-dominated solution sets are stored in the archive. The archive is used to store the best estimates of the Pareto front and is updated in each search iteration. The archive updating process contains two steps:

a. Firstly, the newly generated solution sets are combined with the non-dominated solution sets already stored in the archives. Then the dominated solutions are removed

b. Secondly, if the archive maximal size is reached, a recurrent truncation method based on crowding distance is 
utilized to remove the least "promising" non-dominated solutions.

3. The diversity - based performance metric, given by $\alpha \in[0$, 1], of the solutions stored in the archive is calculated. $\alpha$ Estimates the level of uniformity in the distribution of solutions in the archive set, i.e., if $\alpha=1$ then the solutions are uniformly distributed, whereas with $\alpha=0.6$ we may approximate that $40 \%$ of the solutions are not evenly distributed. Note that with $\alpha=0$, the archive set is empty.

4. The current stage of food forage is determined according to the diversity of the archive set. Three stages or phases are distinguished: exploration, transition and exploitation.

Table 1. Bee colony structure based on diversity $\alpha$

\begin{tabular}{cc}
\hline Bee type & Size \\
\hline Elite & $(i-\alpha-s) k$
\end{tabular}

$\begin{array}{cc}\text { Follower } & \alpha \mathrm{k} \\ \text { Scout } & \mathrm{S} \mathrm{k} ; \\ & \quad(\mathrm{s}=1 / \text { number of variables })\end{array}$

5. The bee colony structure (i.e., ratios of elite, follower and scout bees) is adjusted according to $\alpha$. This adjustment aims at maximizing $\alpha$ (i.e., increase the distribution uniformity of the solutions). The goal is to make the solutions in the archive set evenly distributed. Note that the archive size $(\mathrm{K})$ is equal to the population size.

Table 1 lists the different bee type ratios which were devised according to the following considerations:

a. In typical experiments, the generated solution sets exhibit low diversity during the initial phase (i.e., $\alpha$ is low). In such cases the percentage of elite bees performing the waggle dance should be high (i.e., $1-\alpha$ to be high) so that exploration is emphasized. As the search proceeds, the archive set eventually becomes more diversified; the elite bee ratio should then be decreased to facilitate local fine tuning.

b. So according to the fitness (i.e., crowding distance) of individual solutions, $(1-\alpha-s) K$ of the bees are selected as elite ones. After that, waggle dance is performed by the elite bees. Note that the number of scout bees is fixed throughout the search.

6. The flying patterns (i.e., the bees' search paths) are also subjected to variation. The scout bees use a polynomial mutation operator (promoting an increase in spread) to explore the search space further. The associated mutation probability is fixed. In contrast, elite and follower bees utilize the Simulated Binary Crossover (SBX) method to exploit the near-optimal generated solutions. The adjustment of flying patterns is achieved through the automated tuning of SBX's distribution index. This is being performed in each iteration. The diversity-based performance metric is again utilized to drive this adjustment.

7. Then, based on the adjusted flying patterns, the bees carry out food foraging.

\subsection{ABC algorithm for Decentralized controller for LFC Problem}

The following $\mathrm{ABC}$ algorithm [15] is adopted for the proposed study
1. Initialize the food source position $X_{i}$ (solutions population) where $i=1,2 \ldots . D$

$\left[X_{i}=1,2,3 \ldots D\right]$

2. Calculate the nectar amount of the population by means of their fitness values using:

$$
f_{i} * t_{i}=1 /\left(1+\text { obj.fun } \cdot i_{\cdot} J\right)
$$

Where $o b j$. fun. represents equation at solution $i$

3. Produce neighbor solution $V_{i j}$ for the Employed bees by using equation

$$
V_{i j}=x_{i j}+\varphi_{i j}\left(x_{i j}-x_{k j}\right)
$$

Where $k=(1,2,3 \ldots . D)$ and $j=(1,2,3 \ldots N)$ are randomly

chosen indexes $\Psi \varphi_{i j}$ is a random number between [-1,1] and evaluate them as indicated in step 2 .

4. Apply the greedy selection process for the Employed bees.

5. If all Onlooker bees are distributed, Go to step 9.otherwise, Go to the next step.

6. Calculate the probability values $P_{i}$ for the solution $X_{i}$ using by equation

$$
P i=\frac{f_{i} * t_{i}}{\sum_{n=1}^{N} f_{i} * t_{i}}
$$

7. Produce the neighbor solution $V_{i}$ for the Onlookers bee from the solution $X_{i}$ selected depending on $P_{i} \quad$ and evaluate them.

8. Apply the greedy selection process for the Onlooker bees.

9. In $A B C$ algorithm, providing that a position cannot be improved further through a predetermined number of cycles, then that food source is assumed to be abandoned. The value of pre determined number of cycles is an important control parameter of the $\mathrm{ABC}$ algorithm, which is called "limit" for abandonment. Assume that the abandoned source is $X_{i}$ and $J=(1,2,3, \ldots, N)$, then the Scout discovers a new food source to be replaced with $X_{i .}$ Determine the abandoned solution for the Scout bees, if it exists, and replace it with a completely new solution $X_{i}^{j}$ using the equation

$$
X_{i}^{j}=X_{\text {min }}^{j}+\operatorname{rand}(0,1) *\left(X_{\text {max }}^{j}-X_{\text {min }}^{j}\right)
$$

and evaluate them as indicated in step2.

10. Memorize the best solution attained so for.

11. If cycle=Maximum Cycle Number (MCN). Stop and print result, otherwise follow step 3 .

The Employed and Onlooker bees select new food sources in the neighborhood of the previous one in their memory depending on visual information. Visual information is based on the comparison of food-source positions. On the other hand, Scout bees, without any guidance while looking for a food-source position, explore a completely new food-source position. Therefore Scout bees are characterized based on their behavior by low search costs and a low average in food-source quality. Occasionally, the Scouts bee can be fortunate to discover rich, entirely unknown food sources. In the case of artificial bee, the artificial Scouts bee could have the fast discovery of the group of feasible solutions as the task. Parameter tuning in meta-heuristic optimization algorithms influences the performances of the algorithm significantly. Divergences, becoming trapped in local extreme and time consumption are such consequences of setting the parameter improperly. The $\mathrm{ABC}$ algorithm as an advantage has a few controlled parameters, since initializing populations "randomly" with a feasible region is sometimes cumbersome. The ABC algorithm does not depend on the initial population to be in a feasible region. Instead, its performance directs the population to the feasible region sufficiently. 


\section{RESTORATION INDICES}

The availability of units in each area with their storage units, with enough margins to pick up the overload ensures whether the load disturbances or disturbance due to the outage of the units have to be given prime importance or not. In this section evaluation index namely Feasible Restoration Indices and Complete Restoration Indices are obtained and presented in the appendix A4 and A5. These restoration Indices indicate whether the system is in a condition to be restored which can be adjudged with various case studies.

The following steps are adopted to find the Restoration Indices:

I.PSR Index $\left(\mathrm{I}_{1}\right)$, Based on Stability (settling time of $\Delta \mathrm{F}_{1}$ )

1) Read $[\mathrm{A}]$, [B], [Г] matrices.

From $[\mathrm{Y}]=[\mathrm{C}][\mathrm{X}]$

2) Solve equation (1) i.e. $\dot{X}=\mathrm{Ax}+\mathrm{Bu}+\Gamma \mathrm{d}$ using Runge Kutta method [16] for a step load disturbance of $1 \%$ in area- 1 of TATURIPS.

3) From the output response of $\Delta F_{1}$ for $1 \%$ step load change in area- 1 obtain the settling time $\zeta_{\mathrm{s}}$ of $\Delta \mathrm{F}_{1}$.

4) PSR Index is obtained as the ratio between the settling time of $\Delta \mathrm{F}_{1}$ and power system time constant. i.e. $\varepsilon_{1}$, this is referred as the Feasible Restoration Index (FRI).

II. PSR Index $\left(\mathrm{I}_{1}\right)$, Based on peak overshoot /undershoot of $\Delta \mathrm{f}$

5) Steps 1 and 2 are repeated.

6) From the output response of $\Delta \mathrm{F}_{1}$ for step load disturbances of $1 \%$ in area-1, the peak undershoot of $\Delta \mathrm{F}_{1}$ is obtained from which PSR Index $\varepsilon_{2}$ is obtained.

III.PSR Index $\left(\mathrm{I}_{2}\right)$,Based on the control input deviation

7) Steps 1 and 2 are repeated

8) From the control input deviation for $1 \%$ step load change in area-1,the PSR Index $\varepsilon_{3}$ is obtained using Lagrangian's Interpolation method [16],

PSR Index $I_{1}, I_{2}$ are indices of Feasible Restoration Index when the system is operating in a

normal condition with both units in operation where,

$\mathrm{I}_{1}=\operatorname{Min}\left\{\epsilon_{1}, \epsilon_{2}\right\}$ and $\operatorname{Max}\left\{\epsilon_{1}, \epsilon_{2}\right\} ; \mathrm{I}_{2}=\epsilon_{3}$.

The FRI computations which are based on the settling time of the output responses related to frequency deviations of both areas in TATURIPS,FRI can be given as

$$
\begin{gathered}
F R I_{\text {max }}=\operatorname{Max}\left\{F R I_{1}, F R I_{2}, F R I_{3}, F R I_{4}, F R I_{5}, F R I_{6}\right\} ; \\
\left.F R I_{\text {min }}=\operatorname{Min}_{F R I_{1}}, F R I_{2}, F R I_{3}, F R I_{4}, F R I_{5}, F R I_{6}\right\}
\end{gathered}
$$

IV.Complete Restoration Indices (Based on outage)

10) Read $[\mathrm{A}],[\mathrm{B}],[\Gamma]$ matrices.

$$
\text { From }[\mathrm{Y}]=[\mathrm{C}][\mathrm{X}]
$$

11) Obtain the modified $[\mathrm{A}],[\mathrm{B}],[\Gamma]$ matrices by considering outage of one unit in area-1 of a TATURIPS.

12) Steps (3) to (8) are repeated for finding PSR Indices $I_{1}, I_{2}$ by considering outages in one of the units in each area of TATURIPS which are the indices for Complete Restoration Index (i.e)

$$
C R I=\left\{F R I_{1}, F R I_{2}, F R I_{3}, \ldots, F R I_{11}, F R I_{12}\right\}
$$

$\left.C R I_{\max }=\operatorname{Max}_{F R I_{1}}, F R I_{2}, F R I_{3}, \ldots, F R I_{11}, F R I_{12}\right\}$ and

$C R I_{\min }=\operatorname{Min}\left\{F R I_{1}, F R I_{2}, F R I_{3}, \ldots, F R I_{11}, F R I_{12}\right\}$

V. For Comprehensive Assessment using Indices

The above steps are repeated in carrying out the PSR Indices

(i) for a step load disturbance of $1 \%$ in area-2.

(ii) for a step load disturbance of $4 \%$ in area-1 and then in area-2.

(iii) by considering SMES unit in Area-1 and GT in Area-2 of TATURIPS (I) to (IV) and then Step (V)- (i), (ii) are repeated.

The amount of max peak (or percentage) overshoot/undershoot directly indicate the relative stability of the system. In the transient response specification the max overshoot and the rise time conflict with each other. In other words, both the max overshoot and rise time cannot be made smaller simultaneously. If one of them is made smaller and the other necessarily becomes larger [17].

\section{SIMULATION RESULTS AND OBSERVATION}

The response of the proposed controllers for the TATURIPS with SMES and GT units for different case studies of the output response of the system shows a good improvement in the performance of the system. The case study has been carried out for load change of $1 \%$ and $4 \%$ as well as with outaged conditions which can be considered as an uncertainty that occurs in an interconnected power system. The Feasible Restoration Index (FRI) are obtained for different load conditions and Complete Restoration Index (CRI) with outage of one unit and/or outage of Distribution Generation Capacity. Figures 1(a), 1(b) to 6(a), 6(b) represent the respective frequency responses and control input deviations of the case study 1 to 6 i.e. Feasible Restoration responses. Figures 7(a), 7(b) to 12(a), 12(b) represent the Complete Restoration responses. The results of the $\mathrm{ABC}$ tuned gain values coordinated with DAC, their respective settling time, FRI, CRI and also the peak over shoot value $\left|\epsilon_{1}\right|$ of all the case study has been presented in the table 2 and 3 . The proposed methodology with respect to the settling time as well as frequency deviations has been analyzed and is presented as an index for normal operation with load changes and for outage condition also.

Power System Restoration Assessment:-

a) based on Settling Time

(i) If FRI or CRI is greater than 1 then more amount of distributed generation requirement is needed.

b) based on peak undershoot of $\Delta \mathrm{F}_{1}\left|\epsilon_{1}\right|$

(i) If FRI or CRI in greater than 0.085 then the system is vulnerable and the system becomes If FRI or CRI is $0.02 \leq\left|\epsilon_{1}\right| \geq 0.104$ then more unstable and may result to blackout.

(ii) amount of distribution generation requirement is needed.

(iii) If FRI or CRI is greater than 0.104 not only more amount of distributed generation is required but also load shedding is preferable. 
Table 2. Restoration Index Values

\begin{tabular}{|l|l|l|l|l|l|l|c|c|}
\hline $\begin{array}{l}\text { Case } \\
\text { study }\end{array}$ & \multicolumn{1}{|c|}{ System } & $\Delta \mathrm{P}_{\mathrm{d}}$ & $\mathrm{K}_{\mathrm{P}}$ & $\mathrm{K}_{\mathrm{I}}$ & $\begin{array}{c}\Delta \mathrm{f} \\
\mathrm{in} \\
\mathrm{sec}\end{array}$ & $\begin{array}{c}\mathrm{RI} \\
\text { settling } \\
\text { time } \\
\text { on } \\
\text { bes } \\
\text { peak } \\
\text { on } \\
\text { based } \\
\text { shoot } \\
\text { of } \Delta \mathrm{F} \\
\epsilon_{2}\end{array}$ & $\begin{array}{c}\text { Based on } \\
\text { control } \\
\text { input } \\
\text { deviation } \\
\epsilon_{3}\end{array}$ \\
\hline CASE 1 & TATURIPS +DAC & $1 \%$ & 0.59 & 0.38 & 20 & 1 & 0.02 & 0.0035 \\
\hline CASE 2 & TATURIPS+SMES+DAC & $1 \%$ & 0.40 & 0.19 & 17 & 0.85 & 0.021 & 0.0043 \\
\hline CASE 3 & TATURIPS+GT+DAC & $1 \%$ & 0.87 & 0.42 & 18 & 0.9 & 0.024 & 0.014 \\
\hline CASE 4 & TATURIPS+DAC & $4 \%$ & 0.47 & 0.27 & 21 & 1.05 & 0.081 & 0.03 \\
\hline CASE 5 & TATURIPS+SMES+DAC & $4 \%$ & 0.55 & 0.27 & 17.5 & 0.87 & 0.082 & 0.03 \\
\hline CASE 6 & TATURIPS+GT+DAC & $4 \%$ & 0.75 & 0.19 & 19 & 0.95 & 0.085 & 0.04 \\
\hline CASE 7 & TATURIPS+DAC & $1 \%$ & 0.59 & 0.38 & 21 & 1.05 & 0.025. & 0.0057 \\
\hline CASE 8 & TATURIPS+SMES+DAC & $1 \%$ & 0.40 & 0.19 & 18 & 0.9 & 0.025 & 0.0072 \\
\hline CASE 9 & TATURIPS+GT+DAC & $1 \%$ & 0.87 & 0.42 & 19 & 0.95 & 0.03 & 0.024 \\
\hline CASE10 & TATURIPS+DAC & $4 \%$ & 0.47 & 0.27 & 23 & 1.15 & 0.098 & 0.065 \\
\hline CASE11 & TATURIPS+SMES+DAC & $4 \%$ & 0.55 & 0.27 & 19 & 0.95 & 0.1 & 0.04 \\
\hline CASE12 & TATURIPS+GT+DAC & $4 \%$ & 0.75 & 0.19 & 20 & 20 & 0.104 & 0.04 \\
\hline
\end{tabular}

- CASE 1-6: Both Units in operation

- CASE 7-12: With one unit outaged

Table 3. FRI and CRI Based on Magnitude of $\Delta F_{1}$ and $\Delta P_{C}$

\begin{tabular}{|l|c|c|c|c|c|c|c|c|}
\hline \multirow{3}{*}{ SYSTEM } & \multicolumn{5}{|c|}{$\begin{array}{c}|c| \\
\text { Based on undershoot }\end{array}$} & \multicolumn{3}{c|}{$\begin{array}{c}\epsilon_{3}\left(\Delta P_{c}\right) \\
\text { Based on control input deviation }\end{array}$} \\
\cline { 2 - 10 } & \multicolumn{2}{|c|}{ FRI } & \multicolumn{2}{c|}{ CRI } & \multicolumn{2}{c|}{ FRI } & \multicolumn{2}{c|}{ CRI } \\
\cline { 2 - 10 } & $1 \%$ & $4 \%$ & $1 \%$ & $4 \%$ & $1 \%$ & $4 \%$ & $1 \%$ & $4 \%$ \\
\hline TATURIPS & 0.02 & 0.081 & 0.025 & 0.098 & 0.0035 & 0.03 & 0.0057 & 0.065 \\
\hline $\begin{array}{l}\text { TATURIPS + } \\
\text { SMES+DAC }\end{array}$ & 0.021 & 0.082 & 0.025 & 0.1 & 0.0043 & 0.03 & 0.0072 & 0.04 \\
\hline $\begin{array}{l}\text { TATURIPS + } \\
\text { GT+DAC }\end{array}$ & 0.024 & 0.085 & 0.03 & 0.104 & 0.014 & 0.04 & 0.024 & 0.04 \\
\hline
\end{tabular}




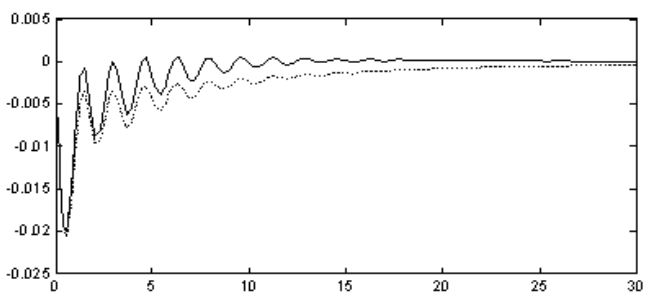

1(a)

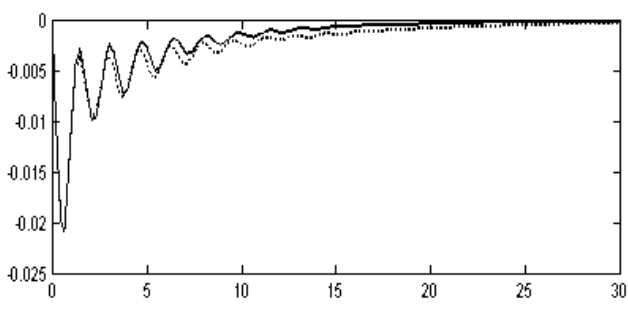

2(a)

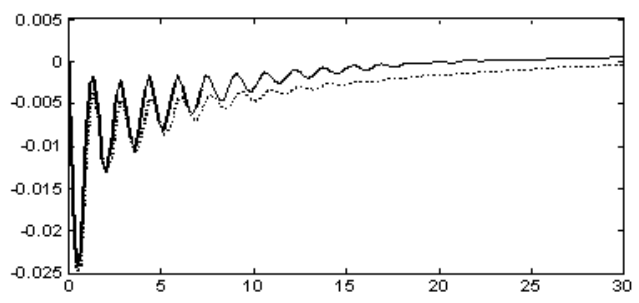

3(a)

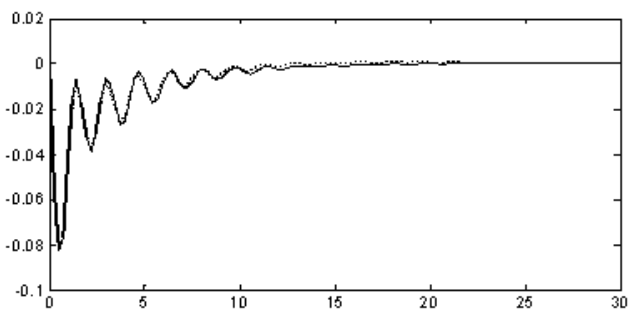

4(a)

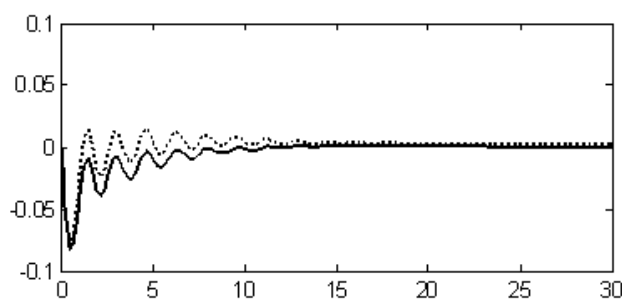

$5(a)$

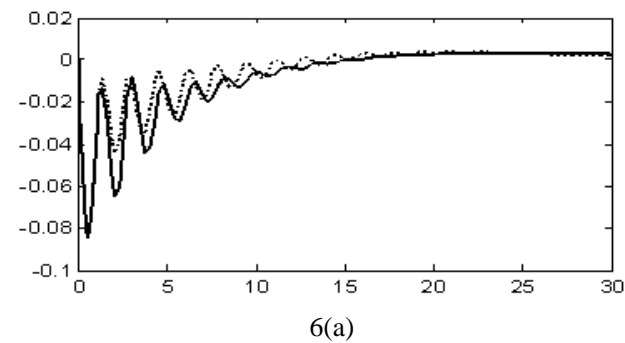

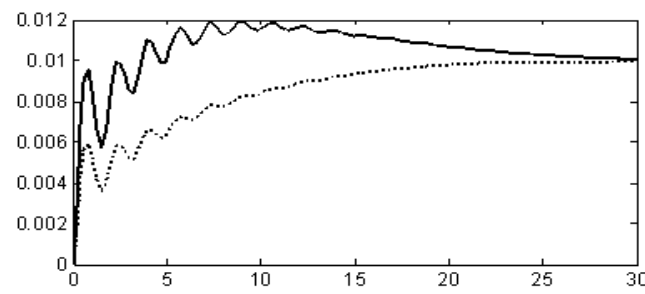

1(b)

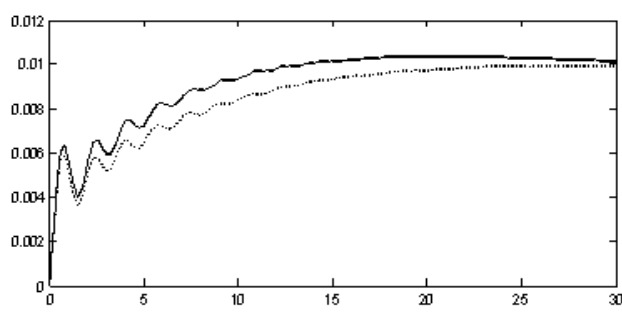

2(b)

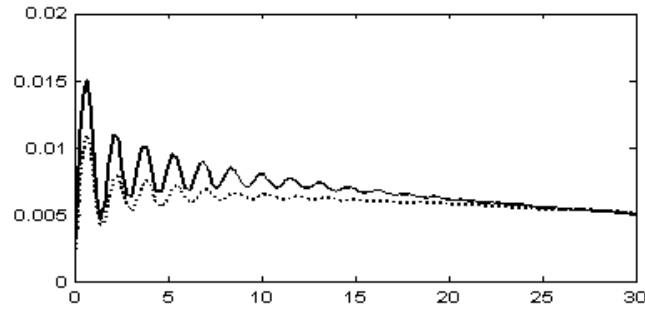

3(b)

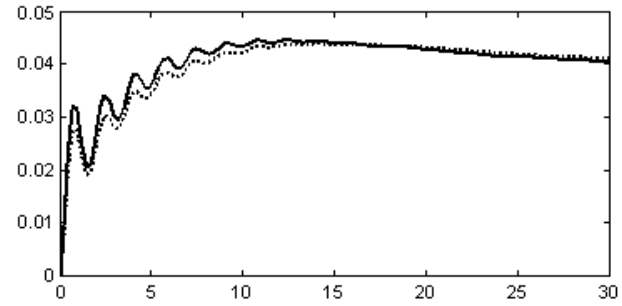

$4(\mathrm{~b})$

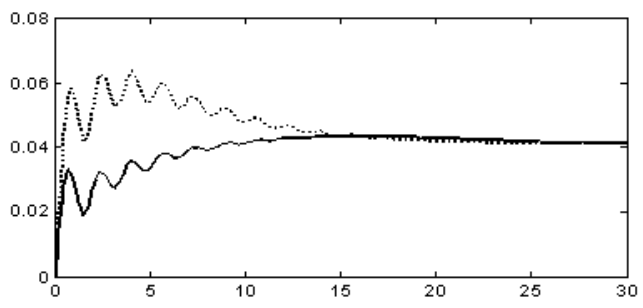

5 (b)

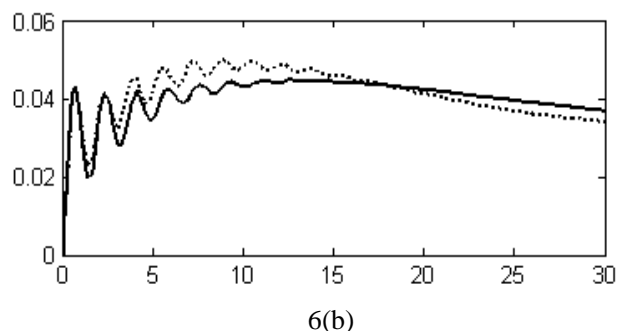

Fig 5: 1(a), 1(b) to 6(a), 6(b) Frequency deviation and Control input deviation for FRI case study; 1(a) to 6(b): $x$ axis - Time in Seconds.

1(a), 2(a), 3(a), 4(a), 5(a), 6(a): $y$ axis - Frequency deviations in $\mathrm{HZ}$. 1(b), 2(b), 3(b), 4(b), 5(b), 6(b): y axis - Control input deviations in p.u MW.

TATURIPS (dotted line), TATURIPS with ABCPI + DAC (solid line). 

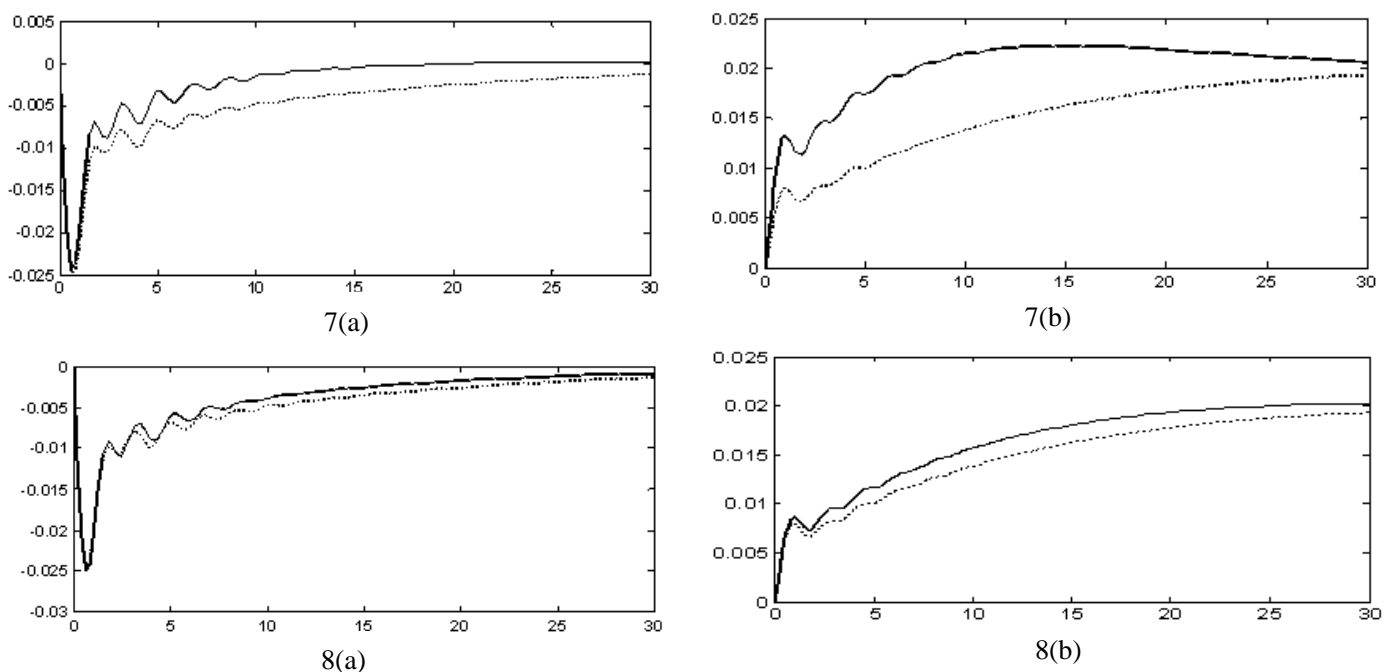

$8(\mathrm{~b})$
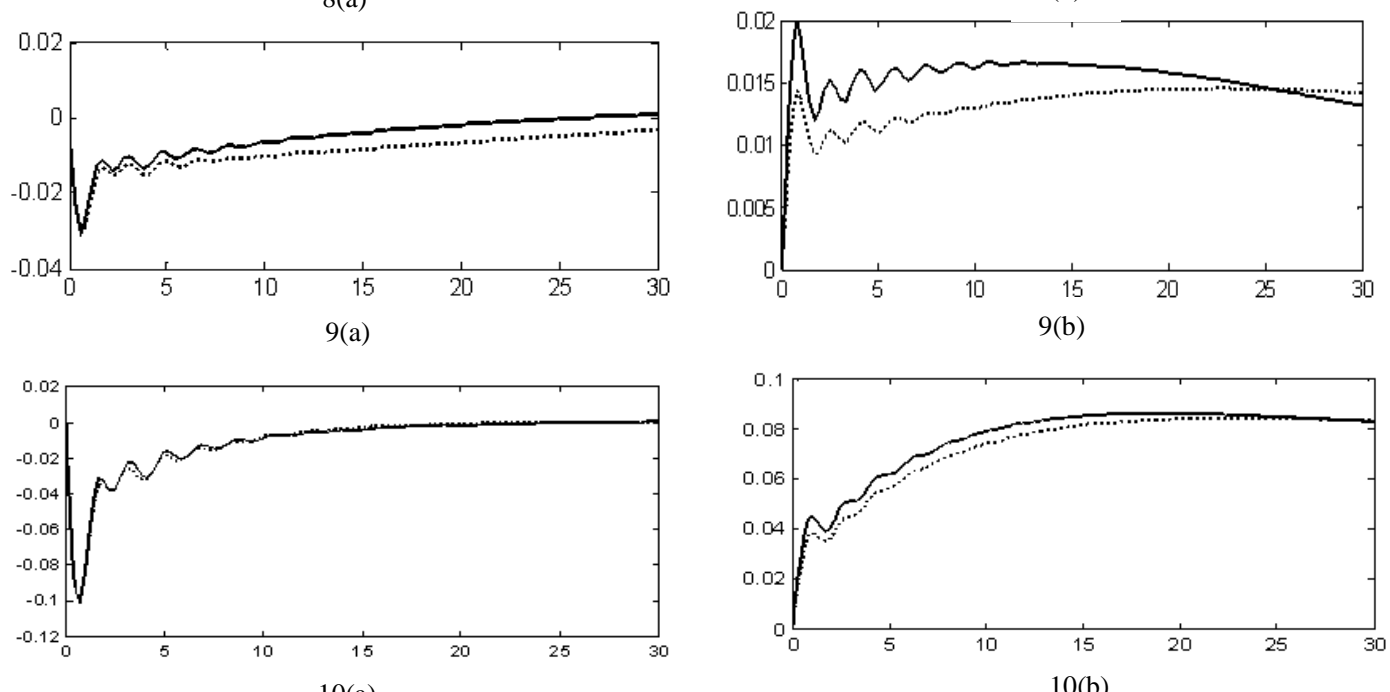

10(a)
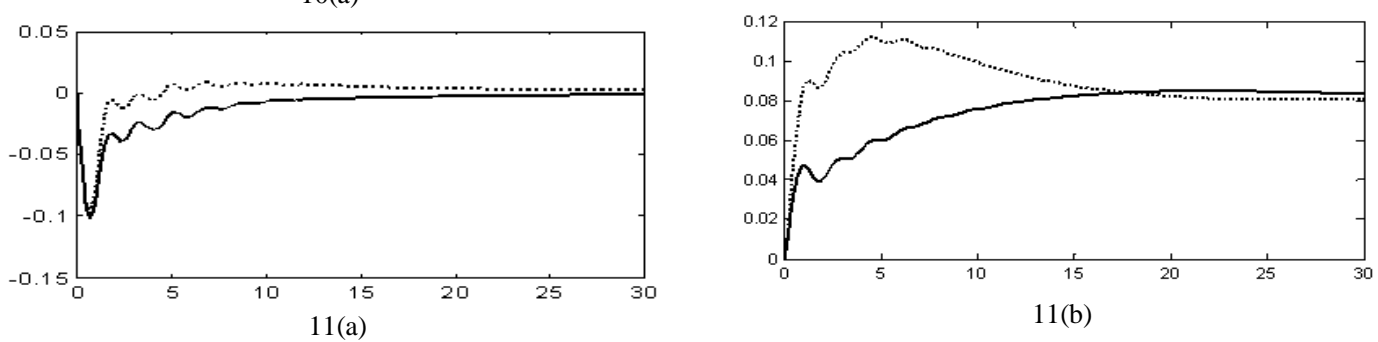

11(b)
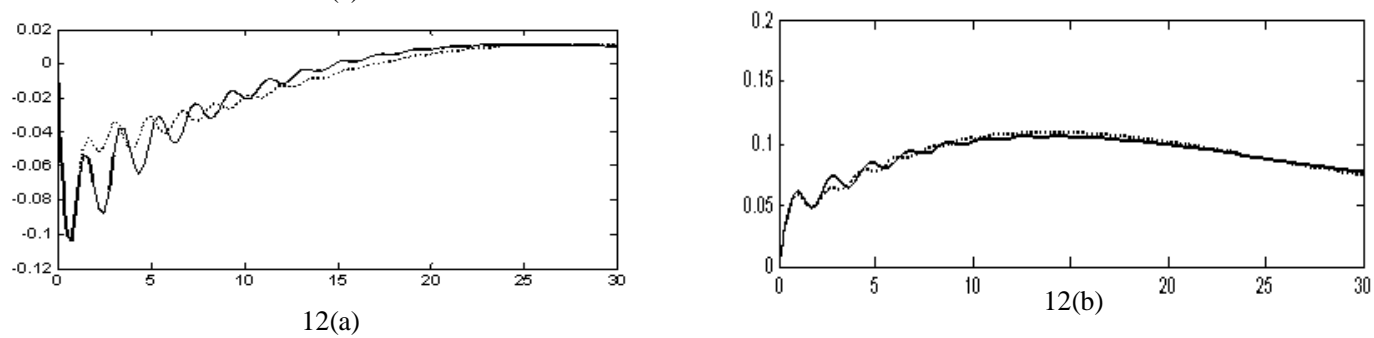

Fig 6: 7(a), 7(b) to 12(a), 12(b) Frequency deviation and Control input deviation for CRI case study; 7(a) to 12(b): $x$ axis - Time in Seconds.

7(a), 8(a), 9(a), 10(a), 11(a), 12(a): $y$ axis - Frequency deviations in $\mathrm{HZ}$.

7(b), 8(b), 9(b), 10(b), 11(b), 12(b): y axis - Control input deviations in p.u MW.

TATURIPS (dotted line), TATURIPS with ABCPI + DAC (solid line). 


\section{CONCLUSIONS}

The proposed methodology has been implemented on TATURIPS considering DAC in both areas and without/with SMES and GT units in Area-1 and Area-2 respectively to meet out even under peak load conditions along with an intelligent controller in each area and to restore the system within a short span of time during inter-area oscillations thereby damping out the peak overshoots and frequency deviations due to a considerable limit of load changes and also during a outage condition. A better stability margin is obtained with both the SMES and GT units compared to that of TATURIPS without DAC, SMES and GT units. Applying the proposed methodology to the system operation, enhances the operating efficiency, securing a full restoration capability, thereby reducing the addition of new power facilities to meet out the load changes. It is clear that the restoration capability can be maintained at high level, thereby increasing the effectiveness of the electric power supply.

\section{ACKNOWLEDGEMENT}

The authors wish to thank the authorities of Annamalai University, Annamalainagar, TamilNadu, India for the facilities provided to prepare this paper.

\section{REFERENCES}

[1] Ibraheem, P. Kumar, D.P. Kothari, "Recent philosophies of automatic generation control strategies in power systems" IEEE Transactions on Power System, Vol.20, No.1, 2005, pp. 346-357.

[2] R.Roy, P.Bhatt, S.P.Ghoshal, "Evolutionary computation based Three-Area Automatic Generation Control", Expert Systems with Applications, Vol 37, 2010, pp.5913-24.

[3] H. Shayeghi, H.A. Shayanfar, A. Jalili, "Load Frequency Control Strategies: A state-of the-art survey for the researcher", Energy Conversion and Management, Vol.50, No.2, 2009, pp.344-353.

[4] Chidambaram, I.A, S.Velusami, "Design of Decentralized Biased Controllers for Load Frequency Control of Interconnected Power Systems" Electric Power Components and Systems, Vol. 33, No.12, 2005, pp. 1313-1331.

[5] Elgerd,O 1 and Fosha,E E “ The MegawattFrequencyControl Problem: A new approach via optimal control theory" IEEE Trans.Pqwer Apparatus \& System,Vol PAS.89, Vol 4, 1970, pp 5.

[6] Johnson,C.D "Theory of Disturbance Accommodation Controllers" in control and dynamic systems; Advances in Theory \& Applications, Vol 12, Academic Press, 1976, pp.387-347.

[7] Demiroren A., "Application of a self-tuning to power system with SMES", European Transactions on Electrical Power (ETEP), Vol. 12, N0.2, 2002, pp. 101109.

[8] S.C.Tripathy, R.Balasubramanian, P.S.Chandramohana Nair, "Adaptive Automatic Generation Control with Super Conducting Magnetic Energy Storage in Power System", IEEE Transactions On Energy Conversion, Vol.7, No.3, 1992, pp. 134-141.

[9] A.Demiroren, E.Yesil, "Automatic generation control With Fuzzy logic controllers in the power system including SMES units", Electrical Power and Energy Systems, Vol:26, 2004, pp.291-305.

[10] R.J. Abraham, D. Das and A. Patra, "Automatic Generation Control of an Interconnected Hydrothermal Power System Considering Superconducting Magnetic
Energy Storage", Electrical Power and Energy Systems; Vol 29, 2007, pp. 271-579.

[11] Soon Kiat Yee, Jovica V.Milanovic, F.Michael Hughes, "Overview and comparative Analysis of Gas Turbine Models for System Stability Studies", IEEE Trans. On Power Systems Vol.23, No.1, 2008, pp. 108-118.

[12] S.Barsali,D.poli,A.Pratico, R.Salvati, M.Sforna,R. Zaottini, "Restoration Islands Supplied by Gas Turbine", Electric Power System Research,Vol.78, 2008, pp. 2004-2010.

[13] D.Karaboga and B.Akay, "A Comparative Study of Artificial Bee Colony Algorithm”, Applied Mathematics and Computation, Vol. 214, 2009, pp. 108-132.

[14] S.N.Omkar, J.Senthil Nath, R.Khandelwal, G.N.Naik and S.Gopalakrishnan, "Artificial Bee Colony $(\mathrm{ABC})$ forMulti-Objective Design Optimization of Composite Structures", Applied Soft Computing, Vol. 11, Issue 1, 2011, pp. 489-499.

[15] D.Karaboga, B.Basturk, “Artificial Bee Colony (ABC) Optimization Algorithm for Solving Constrained Optimization Problems", Advances in Soft Computing: Foundations of Fuzzy Logic and Soft Computing, LNAI.4529, springer-verlag, 2007, pp.789-798.

[16] M. Shanthakumar, 1999.Computer Based Numerical Analysis, Khanna Publishers, New Delhi.

[17] Katsuhiko Ogata, 1986.Modern control Engineering, Prentice Hall of India, New Delhi.

\section{APPENDIX}
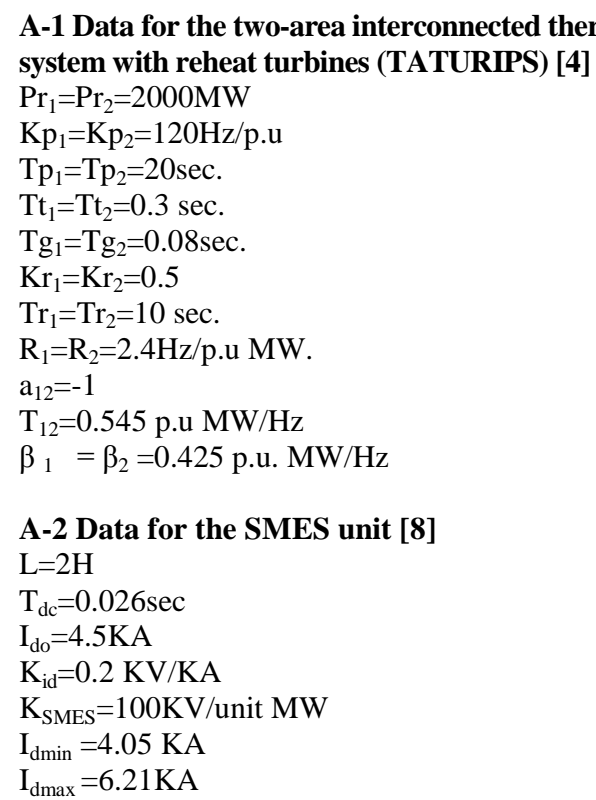

A-3 Data for GT unit [11]

$\mathrm{T}_{1}=10 \mathrm{sec}$

$\mathrm{T}_{2}=0.1 \mathrm{sec}$

$\mathrm{T}_{3}=3 \mathrm{sec}$

$\mathrm{K}_{\mathrm{t}}=1$

$\mathrm{K}_{\mathrm{r}}=0.04$

$\mathrm{D}_{\text {turb }}=0.03$

Max and Min Valve Position $=1$ and -0.1

\section{A-4 Feasible Restoration Indices}

The optimal Proportional plus Integral controller gains are obtained using PSO technique for TATURIPS with/without distributed generations. The various case studies that have 
been carried out for framing the Feasible Restoration Indices were obtained based on the settling time of the output response of the frequency deviations in both areas as follows:

Case 1: In the TATURIPS with $1 \%$ step load disturbance in area-1; the settling time $\left(\tau_{\mathrm{s} 1}\right)$ of the frequency deviation in area- 1 is obtained and $\mathrm{FRI}_{1}$ is found as

$$
F R I_{1}=\tau_{s 1} / T_{p}
$$

Case 2: In the TATURIPS considering SMES and GT in Area-1 and Area-2 respectively with 1\% step load disturbance in area1 and the settling time $\left(\tau_{\mathrm{s} 2}\right)$ of the frequency deviation in area-1 is obtained and $\mathrm{FRI}_{2}$ is found as

$$
F R I_{2}=\tau_{s 2} / T_{p}
$$

Case 3: In the TATURIPS considering SMES and GT in Area-1 and Area-2 respectively with $1 \%$ step load disturbance in area 2 and the settling time $\left(\tau_{\mathrm{s} 3}\right)$ of the frequency deviation in area-2 is obtained and $\mathrm{FRI}_{3}$ is found as

$$
F R I_{3}=\tau_{s 3} / T_{p}
$$

Case 4:In the TATURIPS with 4\% step load disturbance in area-1; the settling time $\left(\tau_{\mathrm{s} 4}\right)$ of the frequency deviation in area-1 is obtained $\mathrm{FRI}_{4}$ is found as

$$
F R I_{4}=\tau_{s 4} / T_{p}
$$

Case 5: In the TATURIPS considering SMES and GT in Area-1 and Area-2 respectively with $4 \%$ step load disturbance in areal and the settling time $\left(\tau_{\mathrm{s} 5}\right)$ of the frequency deviation in area-1 is obtained and $\mathrm{FRI}_{5}$ is found as

$$
F R I_{5}=\tau_{s 5} / T_{p}
$$

Case 6: In the TATURIPS considering SMES and GT in Area-1 and Area-2 respectively with 4\% step load disturbance in area- 2 and the settling time $\left(\tau_{\mathrm{s} 6}\right)$ of the frequency deviation in area-2 is obtained and $\mathrm{FRI}_{6}$ is found as

$$
F R I_{6}=\tau_{s 6} / T_{p}
$$

Where $\tau_{\mathrm{s} 1}, \tau_{\mathrm{s} 2}, \tau_{\mathrm{s} 3}, \tau_{\mathrm{s} 4}, \tau_{\mathrm{s} 5}, \tau_{\mathrm{s} 6}$ are the settling time of the (frequency deviation) output response of the system for various case studies respectively and $T_{p}$ is the power system time constant. The maximum and minimum Feasible Restoration Indices are obtained as follows:

$$
\begin{aligned}
& F R I_{\max }=\operatorname{Max}\left\{F R I_{1}, F R I_{2}, F R I_{3}, F R I_{4}, F R I_{5}, F R I_{6}\right\} \\
& F R I_{\text {min }}=\operatorname{Min}\left\{F R I_{1}, F R I_{2}, F R I_{3}, F R I_{4}, F R I_{5}, F R I_{6}\right.
\end{aligned}
$$

\section{A-5 Complete Restoration Indices}

Apart from the normal operating condition of the TATURIPS few other case studies like outage of one distributed generation in TATURIPS are considered with $1 \%$ and $4 \%$ step load disturbances. The various case studies obtained based on their optimal gains and their performance index is designated by CRI as follows:

Case7: In the TATURIPS with one unit outaged in area-1and with $1 \%$ stepload disturbance; the settling time is $\left(\tau_{\mathrm{s} 7}\right)$ of the frequency deviation in area- 1 is obtained and $\mathrm{FRI}_{7}$ is found as

$$
F R I_{7}=\tau_{s 7} / T_{p}
$$

Case8: In the TATURIPS considering SMES and GT in Area1 and Area- 2 respectively with $1 \%$ stepload disturbance in areal and the settling time $\left(\tau_{\mathrm{s} 8}\right)$ of the frequency deviation in area- 1 is obtained and $\mathrm{FRI}_{8}$ is found as

$$
F R I_{8}=\tau_{s 8} / T_{p}
$$

Case9: In the TATURIPS considering SMES and GT in Area1 and Area-2 respectively with $1 \%$ stepload disturbance in area 2 and the settling time $\left(\tau_{\mathrm{s} 9}\right)$ of the frequency deviation in area-2 is obtained and $\mathrm{FRI}_{9}$ is obtained as

$$
F R I_{9}=\tau_{s 9} / T_{p}
$$

Case10: In the TATURIPS with one unit outaged in area-1and with $4 \%$ stepload disturbance; the settling time is $\left(\tau_{\mathrm{s} 10}\right)$ of the frequency deviation in area- 1 is obtained and $\mathrm{FRI}_{10}$ is found as

$$
F R I_{10}=\tau_{s 10} / T_{p}
$$

Case11: In the TATURIPS considering SMES and GT in Area-1 and Area-2 respectively with $4 \%$ stepload disturbance in area1 and the settling time $\left(\tau_{s 11}\right)$ of the frequency deviation in area- 1 is obtained and $\mathrm{FRI}_{11}$ is found as

$$
F R I_{11}=\tau_{s 11} / T_{p}
$$

Case 12: In the TATURIPS considering SMES and GT in Area-1 and Area-2 respectively with $4 \%$ stepload disturbance in area- 2 and the settling time $\left(\tau_{\mathrm{s} 12}\right)$ of the frequency deviation in area- 2 is obtained and FRI 12 is obtained as

$$
\begin{gathered}
F R I_{12}=\tau_{s 12} / T_{p} \\
C R I=\left\{F R I_{1}, F R I_{2}, F R I_{3}, \ldots, F R I_{11}, F R I_{12}\right\} \\
C R I_{\text {max }}=\operatorname{Max}_{\left.F R I_{1}, F R I_{2}, F R I_{3}, \ldots, F R I_{11}, F R I_{12}\right\} \text { and }} \\
\left.C R I_{\text {min }}=\operatorname{Min}_{F R I_{1}}, F R I_{2}, F R I_{3}, \ldots, F R I_{11}, F R I_{12}\right\}
\end{gathered}
$$

Apart from the FRI and CRI computations which are based on the settling time of the output response of $\Delta F_{1}$ in TATURIPS with various case studies, the magnitude of $\Delta \mathrm{F}_{1}$ can also be used for finding FRI and CRI

\section{AUTHORS PROFILE}

R. Jayanthi received her B.E and M.E degrees from Faculty of Engineering and Technology, Annamalai University, Annamalai Nagar, Chidambaram, India in 1994 and 2007 respectively. Currently working as an Assistant Professor in the Department of Electrical Engineering, Annamalai University, Annamalai Nagar, since 2007. She is currently working towards the Ph.D. degree. Her research interest includes power system operation and control. Department of Electrical Engineering, Annamalai University, Annamalainagar- 608002, Tamilnadu, India, 
Dr.I.A.Chidambaram (1966) received Bachelor of Engineering in Electrical and Electronics Engineering (1987) Master of Engineering in Power System Engineering (1992) and Ph.D. in Electrical Engineering (2007) from Annamalai University, Annamalainagar. During 1988 - 1993 he was working as Lecturer in the Department of Electrical Engineering, Annamalai University and from 2007 he is working as PROFESSOR in the Department of Electrical Engineering, Annamalai University, and Annamalainagar. $\mathrm{He}$ is a member of ISTE and Indian Science Congress (ISC). His research interests are in power systems, electrical measurements and control systems. (Electrical Measurements Laboratory, Department of Electrical Engineering, Annamalai University, Annamalainagar 608002, Tamilnadu, India, 